\title{
Impact on Biological Markers of a B12 Hypervitaminosis In the Context of a Refractory Vasoplegic Shock Treatment
}

\author{
Philis Yann ${ }^{1 *}$, Degonville James ${ }^{2}$, Boitte Francis ${ }^{1}$ and Mentaverri Romuald ${ }^{1,3}$ \\ ${ }^{1}$ Bone and Endocrine Biology, Amiens University Hospital, France \\ ${ }^{2}$ Biochemistry Laboratory, Amiens University Hospital, France \\ ${ }^{3}$ UR7517, MP3CV, CURS, University de Picardy Jules Verne, France
}

*Corresponding author: Yann Philis, Medicine Resident, Hormonology Laboratory, Amiens University Hospital, Rue du Professor Cabrol, 80000 Amiens, France.

To Cite This Article: Philis Yann, Degonville James, Boitte Francis, Mentaverri Romuald. Impact on Biological Markers of a B12 Hypervitaminosis In the Context of a Refractory Vasoplegic Shock Treatment. Am J Biomed Sci \& Res. 2021 - 12(4). AJBSR.MS.ID.001778. DOI: 10.34297/AJBSR.2021.12.001778.

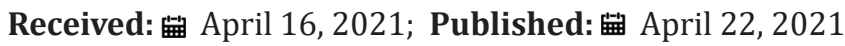

\begin{abstract}
Rationale: Beside its use in cyanure intoxication, hydroxy cobalamin (Vitamin B12) is increasingly used in refractory cardiogenic shock state associated with vasoplegia. Overload tests have shown that the hydroxocobalamin concentrations reached during this type of treatment affect the achievement of the main blood tests. Not being informed about the initiation of this type of treatment could lead to the release of incorrect biological values.
\end{abstract}

Objectives: Evaluate interference induced by hydroxy cobalamin injection on assessment of the common biological markers.

Methods: We present a case report of a 57-year-old female patient who received an hydroxy cobalamin injection (Cyanokit $(5 \mathrm{~g})$, and evaluate blood tests results before, during and after the infusion treatment.

Main Results: We have collected blood tests results before, during and up to 14 days after the treatment initiation. Possible interference - $10 \%$ variation of the concentration or activity within the 2 hours following the injection start - was found on 15 of the 27 biological parameters available.

Conclusions: Observation of some of these interferences reminds us the usefulness of clinical-biological interplay in the management of patients.

Keywords: Biological markers, Biochemistry, Hormonology, Vitamin B12, Interferences, Vasoplegic shock

\section{Introduction}

Vitamin B12 or cobalamin is a water-soluble vitamin, essential for the functioning of the human body, especially for the nervous system. It is mainly found in animal products (meat, eggs, fish). Vitamin B12 is used for several years in the treatment of pernicious anemia, but also at very high doses in cardiogenic or septic shock with major vasoplegic syndrome [1-4].

Thus, patients with a refractory shock state where significant vasoplegia is associated are sometimes treated, as a last resort, with vitamin B12 administered intravenously, with not clear toxicity described so far in the literature and promising results [1-4].
This treatment carried out in a single infusion within 24-hour, is described in the literature as being able to disturb the results of some biological markers, in particular the results of total proteins, transaminases, total bilirubin, creatinine, and hemoglobin levels. These interferences disappear within 12 to 24 hours after the end of the administration for most of the affected parameters. Known interferences are summarized in Table 1 [5].

\section{Case Presentation}

We present here the case of a 57-year-old obese woman with hypertension, diabetes 2 and COPD (Chronic Obstructive 
Pulmonary Disease) presented to the emergency room following a context of nausea / vomiting associated with palpitations that had progressed for several days. Facing a cerebellar syndrome, the patient was hospitalized for 2 days in neurology department. Following a positive SARS-CoV2 PCR, she was transferred to a COVID unit. After 2 unhindered days in this department, the patient presented a sudden respiratory deterioration with desaturation and disturbance of consciousness which prompted an orotracheal intubation and a transfer to cardio-thoracic and vascular intensive care unit at the University Hospital of Amiens-Picardie. The lung CT scan found a focus of right basal pneumonia, suggesting a potential related septic shock. Probabilistic antibiotic therapy with third-generation cephalosporin and metronidazole was therefore started. When she arrived in intensive care unit, regarding this state of shock associated with major vasoplegia, the patient received an appropriate treatment with noradrenaline $5 \mathrm{mg} / \mathrm{h}$, dobutamine 10 $\mu \mathrm{g} / \mathrm{kg} / \mathrm{min}$ and levosimendan. Nonetheless, the cardiogenic shock was refractory to treatment with Left Ventricular Ejection Fraction (LVEF) evaluated at $10 \%$ on echography and signs of left heart failure on the CT scan hence the establishment of an Extra Corporeal Membrane Oxygenation (ECMO). The coronary angiography performed was unremarkable. Despite this adapted treatment, the cardiogenic shock persisted (with a LVEF which did not rise above $15 \%$ ) with the association of a significant vasoplegia due to the severe hypovolemia caused by capillary leakage (albuminemia was not higher than $10 \mathrm{~g} / \mathrm{L}$ ) which justified the introduction of hydroxy cobalamin and terlipressin intravenously, together with massive vascular filling.

In the laboratory, we were not informed about the treatment and were asked to perform vitamin B12 measurement. First determination showed vitamin B12 in the serum (of the sample carried out 30 minutes after the end of the infusion) above 2000 $\mathrm{pg} / \mathrm{mL}$. The serum was checked by the technician and presented a purple color (Figure 1). The color informed us about the presence of an interfering agent in the sample. To determine the exact concentration of cobalamin present in the sample, manual dilutions down to 1:1000 was successively made. Concentration of hydroxy cobalamin was finally estimated at $60.23 \mathrm{mg} / \mathrm{L}$. From this time, we have decided to collect data from anterior blood test and from ulterior results up to 14 days. As shown in Table 2, some of the usual biological markers seem to have been influenced by the major excess of vitamin B12 present in the patient's blood. The serum sodium level remained relatively stable and within normal values, either before or after the vitamin B12 infusion. The same goes for the results of chlorine (at the upper limit of normal range), phosphorus, urea, ultrasensitive troponin Ic (which nonetheless decreased by $10 \%$ due to myocardial distress gradually normalized over time), lipase, fibrinogen, and blood sugar levels. The variations of some other markers seem to correspond perfectly to the patient's clinical progress and to her therapeutic management. This is particularly the case for potassium which rose gradually following an infusion of KCL, for calcium which rose after calcium chlorine injection, and bicarbonates which returned to higher values following the treatment of a decompensated mixed acidosis.

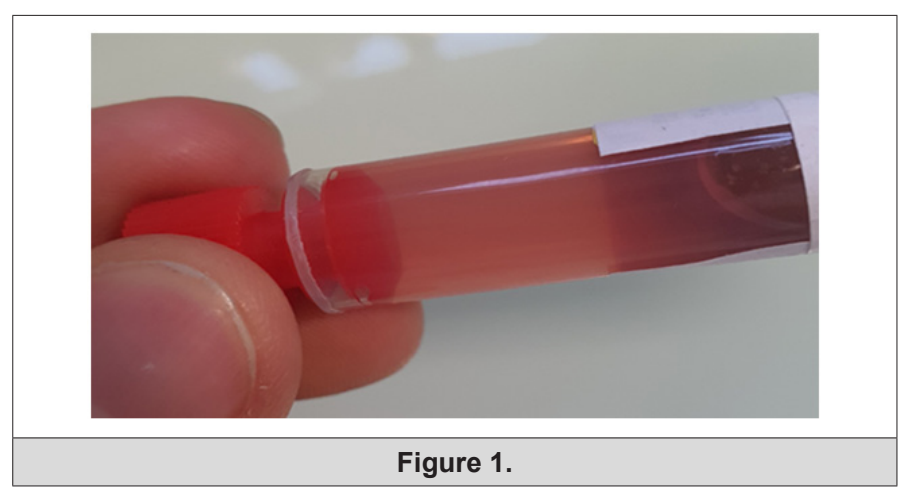

Table 1: [4].

\begin{tabular}{|c|c|c|c|c|c|}
\hline $\begin{array}{l}\text { Laboratory } \\
\text { parameters }\end{array}$ & $\begin{array}{l}\text { No interference } \\
\text { observed }\end{array}$ & Increased result* & Decreased result* & Unpredictable & $\begin{array}{c}\text { Duration of } \\
\text { interference after a } \\
\text { dose of } 5 \mathrm{~g}\end{array}$ \\
\hline Biochemistry & $\begin{array}{l}\text { Calcium } \\
\text { Sodium } \\
\text { Potassium } \\
\text { Chlorine } \\
\text { Urea } \\
\text { Gamma GT }\end{array}$ & $\begin{array}{c}\text { Creatinine } \\
\text { Total and conjugated } \\
\text { bilirubin } \\
\text { Triglycerides } \\
\text { Cholesterol } \\
\text { Total protein } \\
\text { Glucose } \\
\text { Albumin } \\
\text { Alkaline phosphatase }\end{array}$ & ALAT Amylase & $\begin{array}{c}\text { Phosphate } \\
\text { Uric acid } \\
\text { ASAT } \\
\text { CK } \\
\text { LDH }\end{array}$ & $\begin{array}{l}24 \text { hours except for } \\
\text { bilirubin (up to } 4 \text { days) }\end{array}$ \\
\hline
\end{tabular}




\begin{tabular}{|c|c|c|c|c|}
\hline Hematology & $\begin{array}{c}\text { Erythrocytes } \\
\text { Hematocrit } \\
\text { MCV } \\
\text { Leukocytes } \\
\text { Lymphocytes } \\
\text { Monocytes } \\
\text { Eosinophils } \\
\text { Neutrophils } \\
\text { Platelets }\end{array}$ & $\begin{array}{c}\text { Hemoglobin } \\
\mathrm{MCH} \\
\mathrm{MCHC}\end{array}$ & & 12 to 16 hours \\
\hline Coagulation & & & $\begin{array}{l}\text { APTT } \\
\text { INR }\end{array}$ & 24 hours \\
\hline
\end{tabular}

Note*: Interference $\geq 10 \%$ observed with at least one analytical instrument.

Table 2.

\begin{tabular}{|c|c|c|c|c|c|c|c|c|c|}
\hline Parameter & Unit & $\begin{array}{l}\text { Normal } \\
\text { values }\end{array}$ & $\begin{array}{c}40 \text { min before } \\
\text { infusion } \\
\text { beginning }\end{array}$ & $\begin{array}{c}\text { Initial } \\
\text { values } \pm \\
10 \%\end{array}$ & $\begin{array}{c}\text { 1h25 after } \\
\text { infusion } \\
\text { beginning }\end{array}$ & $\begin{array}{c}\text { 13h after } \\
\text { infusion } \\
\text { beginning }\end{array}$ & $\begin{array}{c}\text { 12h after } \\
\text { infusion } \\
\text { end }\end{array}$ & $\begin{array}{l}24 \mathrm{~h} \text { after } \\
\text { infusion } \\
\text { end }\end{array}$ & $\begin{array}{c}\text { Discharge } \\
\text { report } \\
\text { D+14 }\end{array}$ \\
\hline Sodium & $\mathrm{mmol} / \mathrm{L}$ & $135-145$ & 142 & $127,8-156,2$ & 147 & 150 & 147 & 148 & 134 \\
\hline Potassium & $\mathrm{mmol} / \mathrm{L}$ & $3,5-5$ & 2,5 & $2,25-2,75$ & 3,1 & 3,5 & 3,2 & 3,1 & 3,2 \\
\hline Chlorine & $\mathrm{mmol} / \mathrm{L}$ & $98-108$ & 111 & $99,9-122,1$ & 110 & 116 & 115 & 114 & 98 \\
\hline Bicarbonates & $\mathrm{mmol} / \mathrm{L}$ & $24-32$ & 12 & $10,8-13,2$ & 20 & 22 & 21 & 21 & 28 \\
\hline Total proteins & $\mathrm{g} / \mathrm{dL}$ & $5,7-8,2$ & 4,5 & $4,05-4,95$ & 4 & 3,9 & 3,9 & 4,1 & 6,4 \\
\hline Calcium & $\mathrm{mg} / \mathrm{dL}$ & $8,74-10,42$ & 5,45 & $4,91-6$ & 6,33 & 5,93 & 6,4 & 6,5 & 9,4 \\
\hline Phosphorus & $\mathrm{mg} / \mathrm{dL}$ & $3,13-5,81$ & 6,17 & $5,55-6,79$ & 5,57 & 2,32 & 4,7 & 4,4 & 5,1 \\
\hline Creatinine & $\mathrm{mg} / \mathrm{dL}$ & $0,5-0,8$ & 0,66 & $0,59-0,73$ & 1,2 & 1,2 & 1,1 & 1,2 & 0,4 \\
\hline Urea & $\mathrm{mmol} / \mathrm{L}$ & $3,2-8,2$ & 7,7 & $6,93-8,47$ & 8,1 & 9,5 & 11 & 13 & 5,5 \\
\hline Glucose & $\mathrm{mmol} / \mathrm{L}$ & $4,1-5,9$ & 11,4 & $10,26-12,54$ & 10,9 & 4,2 & 9,9 & 6,3 & 5,9 \\
\hline AST & $\mathrm{UI} / \mathrm{L}$ & $13-40$ & 207 & $186,3-227,7$ & 166 & 116 & 71 & 55 & 20 \\
\hline ALT & $\mathrm{UI} / \mathrm{L}$ & $15-40$ & 38 & $34,2-41,8$ & 30 & 28 & 28 & 28 & 23 \\
\hline CK & $\mathrm{UI} / \mathrm{L}$ & $35-145$ & 198 & $178,2-217,8$ & 171 & 127 & NA & 110 & 15 \\
\hline Myoglobin & $\mathrm{ng} / \mathrm{mL}$ & $<83$ & 151 & $135,9-166,1$ & 127 & 118 & NA & 562 & 22 \\
\hline Troponin Ic & $\mathrm{ng} / \mathrm{mL}$ & $<0,034$ & 2,04 & $1,84-2,25$ & 1,84 & 0,84 & NA & 0,1 & 0,1 \\
\hline Lipase & $\mathrm{UI} / \mathrm{L}$ & $12,0-53,0$ & 29 & $26,1-31,9$ & 27 & NA & NA & NA & 41 \\
\hline Total bilirubin & $\mu \mathrm{mol} / \mathrm{L}$ & $5,0-21,0$ & 14 & $12,6-15,4$ & 8 & NA & NA & 5 & 14 \\
\hline $\begin{array}{l}\text { Conjugated } \\
\text { bilirubin }\end{array}$ & $\mu \mathrm{mol} / \mathrm{L}$ & $<3$ & 7 & $6,3-7,7$ & 5 & NA & NA & 3 & 6 \\
\hline WBC & $10.9 / \mathrm{L}$ & $4,0-10,0$ & 6,4 & $5,76-7,04$ & 4,4 & 4,4 & 7,6 & 10 & 7,2 \\
\hline $\mathrm{RBC}$ & $10.12 / \mathrm{L}$ & $3,8-5,2$ & 3,54 & $3,19-3,89$ & 3,32 & 2,78 & 2,5 & 2,6 & 4,2 \\
\hline $\mathrm{Hb}$ & $\mathrm{g} / \mathrm{dL}$ & $11,5-16$ & 11,3 & $10,17-12,43$ & 10,8 & 9 & 8,1 & 8 & 13 \\
\hline MCV & $\mathrm{fl}$ & $80-100$ & 97,5 & $\begin{array}{l}87,75- \\
107,25 \\
\end{array}$ & 96,1 & 94,2 & 94 & 93 & 91 \\
\hline Platelets & $10.9 / \mathrm{L}$ & $150-400$ & 202 & $181,8-222,2$ & 163 & 146 & 150 & 151 & 285 \\
\hline INR & ratio & $<1,2$ & 1,73 & $1,56-1,9$ & 1,67 & 1,55 & 1,4 & 1,3 & 1,1 \\
\hline APTT & ratio & $<1,2$ & 4,54 & $4,09-4,99$ & 2,44 & 1,65 & 2,2 & 1,7 & 1,1 \\
\hline Fibrinogen & $\mathrm{g} / \mathrm{L}$ & $1,8-3,5$ & 2,9 & $2,61-3,19$ & NA & 3 & 3 & 3,1 & NA \\
\hline Anti-Xa activity & $\begin{array}{c}\text { UI anti Xa/ } \\
\text { mL }\end{array}$ & $0,3-0,7$ & 0,85 & $0,77-0,94$ & 0,49 & NA & NA & 0,3 & 0,2 \\
\hline
\end{tabular}


Regarding the parameters hitherto known to be influenced by hypervitaminosis B12 [5]: the ASTs have decreased by $20 \%$, the ALTs have decreased by $21 \%$ but remained low in normal values, the creatine phosphokinase has decreased by $14 \%$, total bilirubin has dropped by $43 \%$ (29\% for conjugated bilirubin) and total proteins have slightly decreased (11\%). Myoglobin has decreased in this case by $16 \%$, despite some authors said they have reported no interference with hypervitaminosis B12 [6]. The most influenced parameter is clearly creatinine which has increased by $81 \%$ within these 2 hours. We have assayed all biochemistry parameters on Atellica IM Siemens®. Hematolocytology parameters have been assayed on XN 9000 Sysmex®, and coagulation parameters have been assayed on CS 5100 Siemens®.

Concerning hematological parameters: hemoglobin ( $\mathrm{Hb})$, red blood cells (RBC) and mean corpuscular volume (MCV) have stayed stable. Conversely, white blood cells (WBC) and platelets have been affected by a decrease of respectively $31 \%$ and $19 \%$. Concerning coagulation markers, it is important to report that Activated Partial Thromboplastin Time (APTT) decreased by $46 \%$ with an Anti-Xa activity following the same kinetics (- $42 \%$ ) whereas no modification in the anticoagulant treatment was made (sodium heparinate $1000 \mathrm{UI} / \mathrm{mL}$ with a $0.6 \mathrm{~mL} / \mathrm{h}$ outflow all along). On the other hand, the International Normalized Ratio (INR) have remained perfectly stable.

This treatment was very effective with a quick rise in blood pressure and a LVEF which normalized after 36 hours. The patient also received dexamethasone treatment for 10 days from day 4 due to lesions evocative of COVID 19 on the CT scan. The patient remained in intensive care unit for a total of 15 days. She was then transferred to rehabilitation and recuperative care facilities to benefit from respiratory rehabilitation with the aim to go back home safely.

\section{Discussion}

We present here the case of a 57-year-old woman who received an hydroxycobalamin and terlipressin injection in the intention to treat a cardiogenic shock. It was not the first time the patient was treated for that as two months earlier she was also hospitalized with a cardiogenic shock of undetermined etiology, refractory to the usual treatment, and which after administration of hydroxycobalamin had rapidly resolved. The etiology remained uncertain with two predominant hypotheses: fulminant myocarditis for which the complete infectious assessment (search for cosackies, enteroviruses, CMV, VZV, HIV, VHC, HBV, HHV6 and campylobacter jejuni) came back negative except for SARS-CoV2 PCR, and TakoTsubo-type stress heart disease in the context of an adrenergic shock setting after repeated administration of adrenergic agonist metoclopramide shortly before the patient's clinical condition deteriorated. The myocardial biopsy performed was histologically perfectly normal. Non-nephrotic proteinuria evaluated at 2.4 grams per day was also reported. The hydroxycobalamin not being known to cause proteinuria and the immunoelectrophoresis of urinary proteins not finding monoclonal free light chains with a albuminuria at $0.25 \mathrm{~g} / \mathrm{L}$, the cause of the proteinurea remains uncertain. Electrophoresis of serum proteins was in favor of an inflammatory syndrome without any monoclonal immunoglobulins and an albuminemia estimated at 52\% (25.6 g/L).

Five grams of hydroxycobalamin (Cyanokit $\AA$ ) were administered intravenously within 24 hours using a $250 \mathrm{~mL}$ infusion of $\mathrm{NaCl} 0.9 \%$. Of note, the half-life of free and total cobalamins in this drug is estimated between 26 and 31 hours [4]. In this study, the authors described hydroxycobalamin concentrations ranging from 400 to $800 \mathrm{mg} / \mathrm{L}$ and from 200-400 mg/L, 30 minutes, and 5 hours after the hydrocobalamin administration, respectively. These phamacokinetics data agree with what we found 12 hours after the end of the infusion $(60.23 \mathrm{mg} / \mathrm{L})$. We were not informed by the physicians of the Cyanokit ${ }^{\circledR}$ treatment. But thanks to the technician's vigilance and the observation of the presence of a strong purple coloration of the sample, we were warned about the possible presence of an interfering agent in our sample. This observation prompted us to determine the exact vitamin B12 value, to evaluate the risk of interference we were facing. Interferences bound to hydroxocobalamin, are whether spectral (with intense absorption peaks at 350, 412 and $524 \mathrm{~nm}$ ), or chemical (bound to reactions with components of the reaction medium) [6]. As Vest et al. [6], we decided to choose a $10 \%$ cut-off to determine whether the interference was effective or not, and to avoid bias linked to measurement uncertainties. The percentages of variation we determined correspond to the variation of the result between 40 minutes before administration and $1 \mathrm{~h} 25$ after the beginning of the infusion, i.e., corresponding to a 2 hours' time lapse which let us exclude high variations due to clinical improvement. In this case report most of the interferences have apparently led to an underestimation of the biological values. Interpretation of low values data are however subject to caution because of higher measure uncertainties, as observed for conjugated bilirubin.

Noteworthy, serum vitamin B12 could be higher than the values we have found. Indeed, in context of cyanide poisoning, it is possible to administer up to 40 grams of hydroxy cobalamin within two hours [6] which of course may generate greater interferences in parameters assayed.

\section{Conclusion}

The administration of hydroxy cobalamin is a therapy of last resort in the treatment of refractory cardiogenic shock with major vasoplegia. The case of this patient confirms the interest of the treatment in refractory cardiogenic shock. However, B12 hypervitaminosis also affect several biological assays. This 
interference clearly needs to be further studied as interpretation of the blood tests carried out during first 12 hours following the beginning of the infusion may not be fully representative of the patient's health status. This case report reminds us that the clinicalbiological dialogue is essential and for now underestimated with crucial information, particularly concerning treatment, which are too often not provided to the laboratory.

\section{References}

1. Patel JJ, Venegas Borsellino C, Willoughby R, Freed JK (2019) High-dose vitamine B12 in vasodilatory shock: a narrative review. Nutr Clin Pract 34(4): 514-520.
2. Roderique JD, VanDyck K, Holman B, Tang D, Chui B, et al. (2014) The use of high dose hydroxycobalamin for vasoplegic syndrome. Ann Thorac Surg 97(5): 1785-1786.

3. Lin Y, Vu TQ (2019) Use of High-Dose Hydroxocobalamin for Septic Shock: A Case Report. A A Pract 12(9): 332-335.

4. Gerdes HJ, Seelhammer TG, Nei S, Diaz Soto J, Nabzdyk CG (2021) Extended Duration Infusion of Hydroxocobalamin for Vasoplegic Rescue in Septic Shock. Cureus 13(2): e13388.

5. Summary of product characteristics. European Medicine Agency.

6. Vest P, Renaudeau C, Tellal S, Ragot C, Renard C (2002) Interference of hydroxocobalamin on the results of usual biochemical assays. Annals of Clinical Biology 60(1): 57-64. 